\title{
Airflow Study of a Closed Room in the Public Spaces and Mass Transportation for Healthy and Safe from The Transmission of Covid 19
}

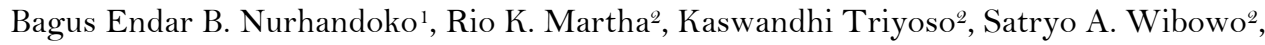 \\ and Sri Widowati ${ }^{3}$
}

Corresponding author. Email: bagus@fi.itb.ac.id

Submitted: 2021-01-11 | Accepted: 2021-04-26 | Published: 202 1-04-30

\begin{abstract}
We present engineering airflow to intercept the transmission of Covid19 in public spaces and public transportations, which relatively fast and simple. This technique is to suppress effectively and as massive as possible the spread of aerosols and droplets contaminated with the COVID-19 virus that is flying in the air by providing a vertical downward flow using fans placed on the ceilings and the use of floors of the certain material so that aerosol and microdroplets will not bounce back up, difficult to roll, and firmly attached to the floor. The numerical airflow simulation shows that positioning the fan on the ceiling of the room will cause the air particle to move faster downward, which will push the microdroplets to fall to the floor more quickly, so that the microdroplets and aerosols will quickly move away from the most risk organs from the transmission, namely the mouth and nose. The contact angle test results on several floor materials always show a value of fewer than 90 degrees. These phenomena cause microdroplets or aerosols that fall to the floor will stick tightly and not easily roll. This phenomenon will cause the room to be more sterile from aerosols and microdroplets that may be contaminated with Covid19. The room will be healthier and safer. This technique can be a solution that is relatively inexpensive and simple to implement on a field scale and is very effective in reducing the radius of the spread of droplets or aerosols in closed spaces, both public spaces and public transportation, such as trains and city buses which are very susceptible to Covid19 transmission.
\end{abstract}

Keywords: COVID-19; engineering air flow; public space; mass transport; contact angle.

\footnotetext{
1) Institut Teknologi Bandung, E-mail: bagusnur@bdg.centrin.net.id; bagus@fi.itb.ac.id

2) Rock Fluid Imaging Lab, Indonesia

3) Telkom University, Indonesia
} 


\section{Airflow Study of a Closed Room in the Public Spaces and Mass Transportation for Healthy and Safe from the Transmission of Covid 19}

Bagus Endar B. Nurhandoko, Rio K. Martha, Kaswandhi Triyoso, Satryo Wibowo, and Sri Widowati

\section{Introduction}

The increase of positive cases of Covid-19 in Indonesia as of January 7, 2021, is still a monotonic increase, with a daily rate of positive cases exceeding 10,000 persons with the number of active cases 114,766 persons or the percentage $14.4 \%$ compared to the world average of $25.81 \%$. The number of cures was 659,437 cases, or $82.7 \%$ compared to the world average of $72.03 \%$. Twenty-three thousand five hundred twenty persons died or $2.9 \%$ compared to the world average of $2.16 \%$. The addition of cases reached the highest number in the addition of daily cases. It was assessed as a result of the long Christmas and New Year 2021 holidays due to the increasing neglect of the public in compliance with the Health protocol discipline (Satgas Penanganan COVID-19, 2021). In this study, we conducted an analysis to reduce the transmission rate of the Covid 19 virus by engineering airflow. Airflow engineering in public spaces is expected to be effective in making droplets or microdroplets move away from the most vulnerable Covid 19 infection zones, namely the nose and mouth. Hopefully, airflow engineering can reduce the risk of Covid 19 transmission rate to be lower.

WHO and almost all governments of countries affected by Covid-19 continue to campaign for the prevention of direct airborne transmission of the virus (WHO, 2020) by disrupting or stopping the risk of being exposed to droplet and aerosol splashes contaminated with the virus through advice on mass wearing facemasks, washing hands, and keeping a safe distance of $1.5-2 \mathrm{~m}$. WHO provided this recommendation to almost all countries to reduce the rate of transmission of covid19 (WHO, 2019). Some studies recommended wearing face masks and using UV for disrupting the transmission of influenza, i.e. (Weiss et al., 2007).

Several studies on the Covid19 Virus conclude that the transmission of this virus is through droplet-shaped liquid splashes, through aerosols flying in the air, and contact with viruscontaminated liquid droplets that fall onto objects' surfaces (WHO, 2020). Some experiments and previous studies for Coronavirus clearly show that it is still possible to spread pathogens that cause acute respiratory tract infections through smaller droplets closer to aerosol size (Tran et al., 2013), (Morawska \& Milton, 2020), (Riediker \& Tsai, 2020). These results show a very high risk of spreading the Covid 19 virus through micrometer-sized liquid droplets (microdroplets) or aerosols because they can hover for longer and have wider coverage, especially in a closed room.

The Covid-19 virus spread from the Covid-19 patient occurs relatively in the horizontal direction where large-diameter liquid droplets fall faster than those with small diameters. Therefore, face masks and maintaining a safe distance are a must to reduce the spread of the virus via these aerosols and droplets.

In the real conditions, i.e., on a city bus, on a train, or in a closed building, are not as perfect as our expectations. There is always a person who does not comply with this seemingly 
simple obligation because they do not understand or feel stuffy due to wearing masks. This non-compliance poses a high risk in terms of transmission.

The risk will be lower when the activity is in the open air or open land exposed to sunlight that contains UV-B (Sagripanti et al., 2012) or UV-C (Nurhandoko, 2020). Exposure to ultraviolet light will effectively inactivate Covid19 (Hindawi et al., 2018). The activity in a closed air circulation space, such as air-conditioned rooms, city buses, trains, Mass Rapid Transport (MRT), will increase transmission risk. The risk of transmission will be even higher because microdroplets will spread widely when coughing or speaking, from the patient to the surrounding persons' mouth and nose.

An experimental study resulted in the Toho University laboratory in collaboration with Japan's NHK TV using a high-sensitivity camera and laser light as shown in Figure 1, proves that aerosols and micro-droplets produced by people talking and sneezing can drift for a long time and spread wider. The experiment showed that the opening ventilation window for 1 hour, aerosol or micro-droplets would be swept out significantly. Therefore, the ventilation system and airflow are crucial to reduce aerosols' concentration and micro-droplets that are likely to have been contaminated with Covid-19.

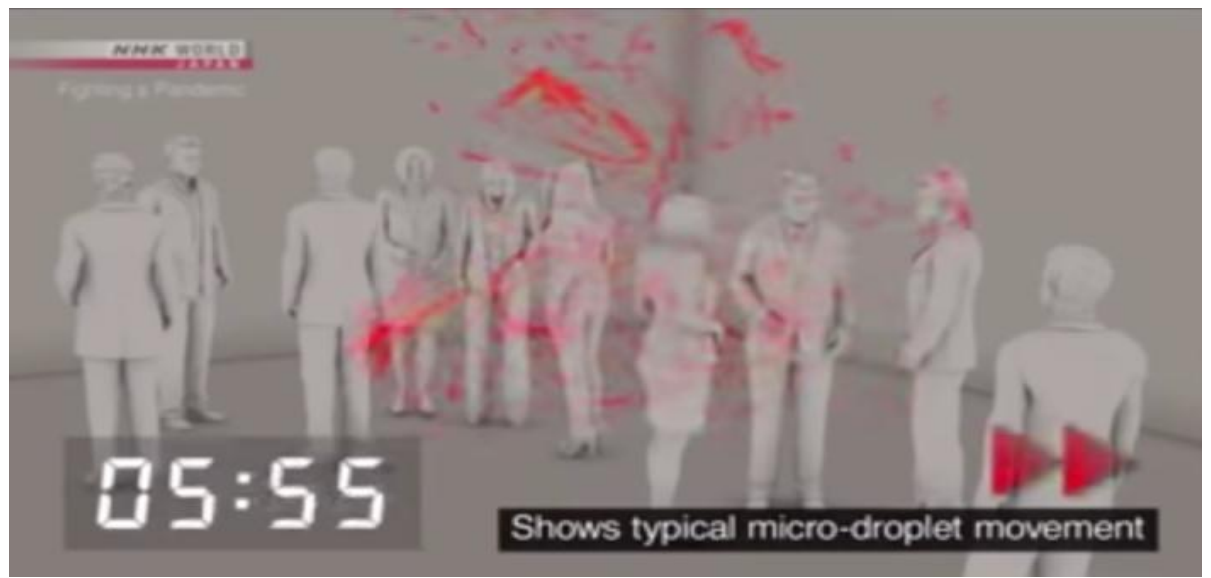

Figure 1. The illustration of virus transmission mechanism through the distribution of microdroplets or aerosols using airflow analysis in closed spaces (Toho University, 2020). The red dots are the distribution of aerosols and micro-droplets flying in the air.

Aerosols and microdroplets are at risk of being contaminated by the Covid-19 virus and can hover in a closed circulation space. This phenomenon can occur in buildings. It can even occur in waiting rooms, patient examination rooms, and even in mass transportation such as trains and city buses.

Covid19 virus transmission in public spaces can be terminated effectively by providing airflow vertically downwards using a fan placed on the ceiling. The downward airflow will suppress the droplets of aerosol and microdroplets that contaminated with viruses so that they immediately flow downwards and immediately fall to the floor, so that they move away from the most susceptible organs to Covid 19 infection, namely the mouth and nose. 
This paper presents airflow modeling result with finite elements to show that the airflow system from the ceiling can effectively suppress aerosol and microdroplets falling to the floor move away from the riskiest zone for Covid 19 transmission, namely the nose and mouth.

The floor material of a room or public vehicle must have a surface tension value between the liquid and the floor that is greater than the surface tension of the liquid against the liquid. This ensures that aerosol particles and microdroplets will not bounce back, have difficulty rolling up, and stick firmly to the floor. This phenomenon will effectively reduce the risk of Covid 19 transmission because falling droplets, micro-droplets, or aerosols will stick tightly to floors or walls. Therefore, the room's floors and walls material must meet these criteria by taking laboratory measurements of the contact angle between the aerosol or droplet and the floor material.

This paper present laboratory measurement results for the contact angle between the liquid and some flooring materials. The observed floor material shows that the contact angle is always less than 90 degrees (hydrophilic). This contact angle value indicates that the surface tension between the liquid and the floor is greater than the liquid's surface tension to the liquid, so that the aerosol grains and microdroplets will stick tightly to the floor, will be difficult to roll, and will not bounce back up. Therefore, the air in the room will be cleaner from aerosols and micro-droplets. UV exposure, mopping, or disinfectant spraying (after all passengers have disembarked) can easily disinfect the contaminated floors. However, the obligation to wear masks massively and maintain a safe distance (1.5 - 2 m) must still be implemented to minimize the risk of transmission.

\section{Methodology}

This technique of blowing air (wind) vertically downwards can be a relatively inexpensive and relatively easy solution to be applied at a field scale. This technique is very effective in reducing the radius of droplets or aerosols in closed circulation spaces (Figure 2), such as in public rooms (kelurahan, sub-district, bank), in mass transportation spaces such as city buses, trains, or markets in buildings, and even in hospital rooms or patient care rooms for corona positive patients. We simulated airflow with a finite element to determine the airflow pattern's characteristics when the fan was turned on above the ceiling.

We analyze and measure the adhesive properties of aerosols or micro-droplets on the floor by measuring the grain shape and contact angle of the droplet liquid with various types of floor materials. 


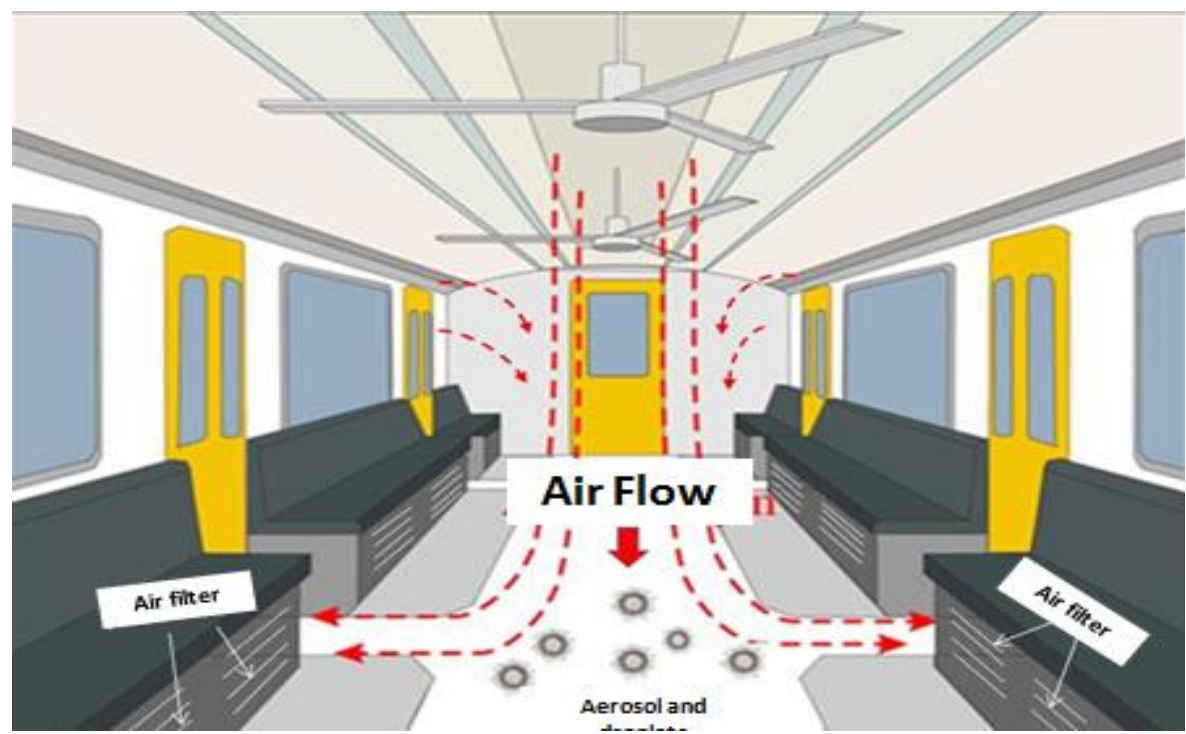

Figure 2. The ceiling fan's airflow can suppress virus-contaminated droplets and aerosols to fall to the floor immediately so that the room can be cleaner from aerosols and droplets.

The dotted line shows the airflow line.

The vertical downward of airflow makes the droplets and aerosols flying in the air to fall as soon as possible. Therefore they do not spread further and move away from the most at risk of transmission body's parts, namely the mouth and nose. Downward air pressure and gravity make droplets, or aerosol droplets stick to the floor more quickly (Figure 2), so that the risk of droplets and aerosols being spread and inhaled by the nose or mouth of the individuals around the patient becomes minimum. Figure 3 shows an illustration of a room's train in which the fan blows the airflow from the ceiling. The air filter under the passenger seat exhausts the aerosol or droplet to fall to the floor more quickly.

Figure 3 shows the atmosphere inside the KRL carriage with route Jakarta-Depok-Bogor. KRL means electric commuter line which operates with route Jakarta, Depok, and Bogor. Airflow blows from the air conditioner on the sides of the carriage. Therefore, we only need to add some fans on the ceiling so that the droplets and aerosol particles flying around immediately fall to the floor. Aerosol and droplets that fall will stick to the floor due to the adhesion mechanism, and the room air will be more sterile. Ideally, this downward vertical airflow is in the "laminar" phase so that the flow line tends to be straight down so that aerosols and droplets can be pushed down as quickly as possible and fall to the floor. One of the ways to achieve laminar flow is using fans with wide wings. With the downward airflow, the air will be cleaner and minimized from aerosols or microdroplets flying around and are likely to be contaminated by Covid 19 viruses. 


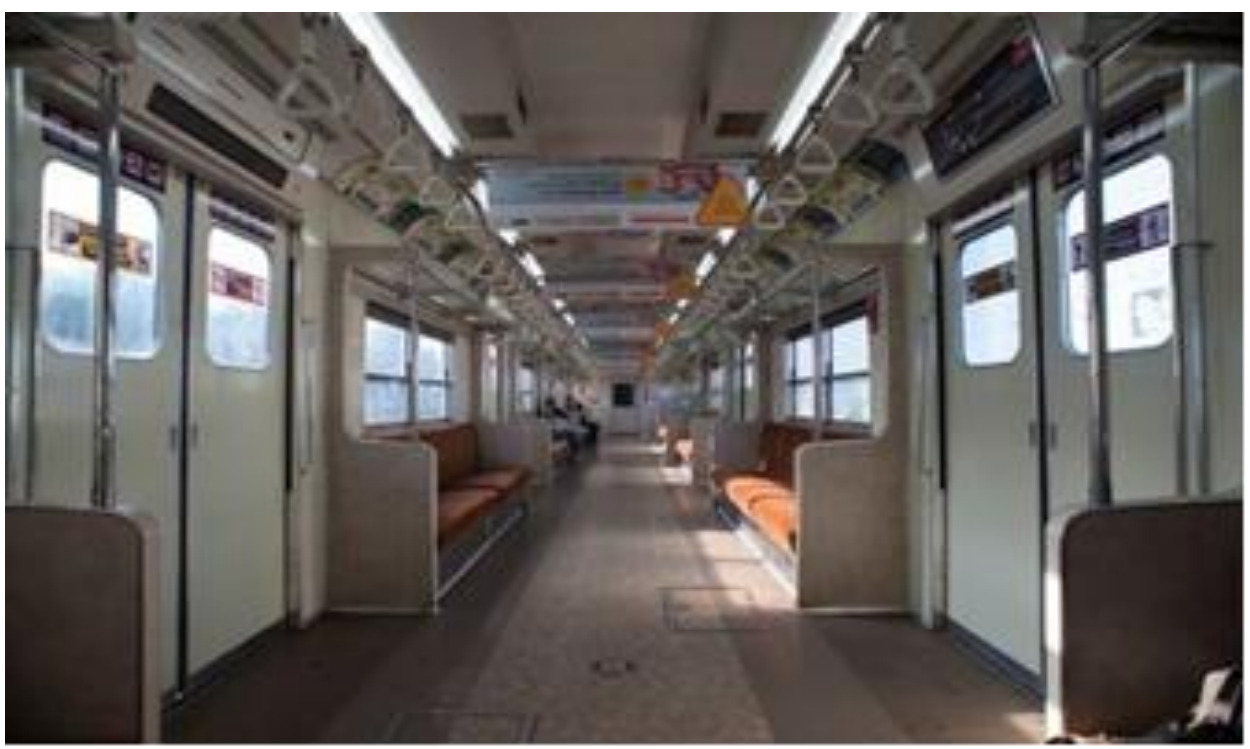

Figure 3. The atmosphere inside the Jakarta-Depok-Bogor KRL Electric Commuter Line. This carriage needs ceiling fans so that aerosols and droplets flying in the air fall as quickly as possible to the floor so that the air becomes sterile from possible micro-droplets contaminated covid 19 .

The technique for intercepting the transmission of viruses or bacteria that contaminate aerosols and droplets through a vertical downward-directed laminar airflow is similar to the commonly used technique in closed room designs to be sterile and even very sterile. This technique has been widely applied in many applications, including the operating room (Aganovic et al., 2017; Bodey et al., 1969; Evans, 2011 a, 2011b; Friberg, 1998). The laminar airflow technique has been used to prevent pathogens' transmission or even avoid particle contamination for biological samples, semiconductor wafers, particle sensitive devices, and even operating rooms (Figure 4). 


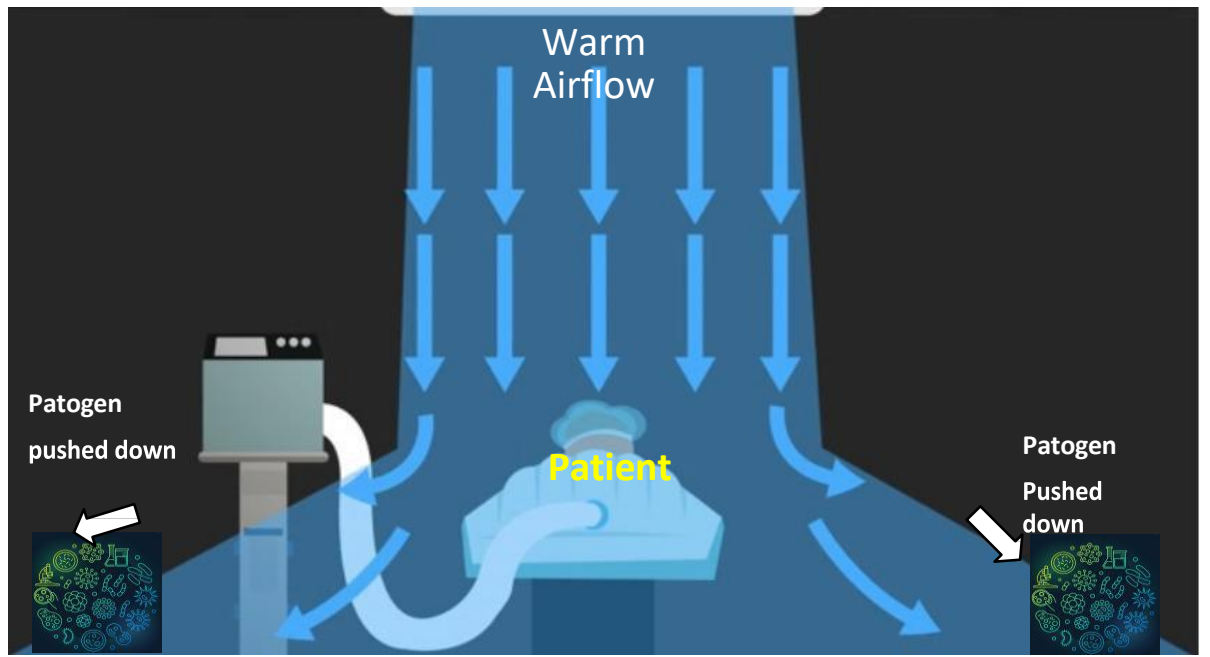

Figure 4. Warm and sterile vertical downward airflow in the patient room

Contact angles are used to characterize the basic properties of solid material, to study the effective properties of the material in its natural state, or to analyze the properties of the material due to the presence of water or fluid fluid (Di Mundo et al., 2018; Holder, 2012; Thomas et al., 2017). In this study, the analysis of droplet fluid adhesion to the floor was carried out by measuring the droplet contact angle and various floor materials using a special microscope for measuring the contact angle, as shown in Figure 5.

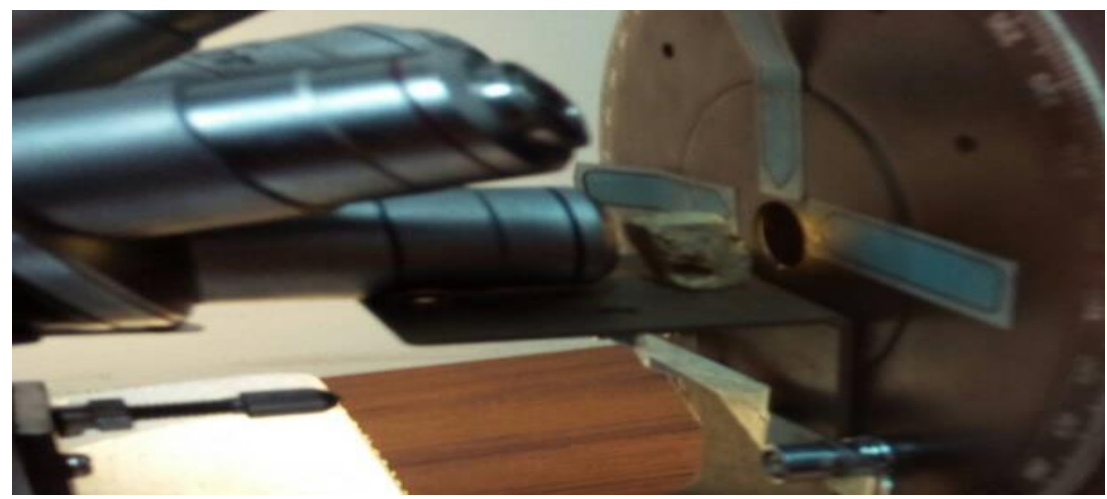

Figure 5. Microscope for measuring contact angle

\section{Results and Discussion}

An experiment of fluid flow distribution pattern due to the fan's positioning on the ceiling in a closed room is carried out numerically with the finite element showing the distribution of air velocity and particles' movement downward (Figure 6). The high-velocity area in the surrounding fan makes the microdroplets and aerosols become fall faster and concentrate on 
the floor. The aerosols and microdroplets will move away from the most risk area or organ, namely the mouth and nose.

In this experiment, a mathematical model is built and analyzed based on partial differential equations that present physical laws such as the momentum equation, which is then solved and simulated. The momentum equation is formed based on the viscosity law of momentum, derived by the differential equation.

$$
\frac{\partial}{\partial t} \rho u_{j}+\nabla \rho u_{j} u_{j}=-\nabla P+\rho \nabla g_{i}+\nabla \tau_{i j}
$$

$\rho$ indicates density of the fluid, $\mathrm{u}$ denotes velocity of the particles, $\mathrm{P}$ is the pressure, $\mathrm{g}$ denotes the acceleration due to gravity. This equation is then solved using the finite element method. The room model is 3 meters in length, 3 meters in width, and 3 meters in height. The fan is positioned on the ceiling with a radius of 0.5 meter, producing a positive pressure of $0.1 \mathrm{~atm}$ against a pressure environment of $1 \mathrm{~atm}$ as shown in Figure 6a. The mesh model is shown in Figure 6 b. The resulting velocityy airflow distribution shown in Figure 6c, this velocity distribution pattern shows that the movement of the particles will be directed downward to the floor. This will cause the concentration of micro droplets in the room's air that are at risk of being contaminated with Covid 19 will drop drastically because the micro droplets and aerosols fall to the floor so that they move away from the most risk organ for a transmission, namely the mouth and nose.

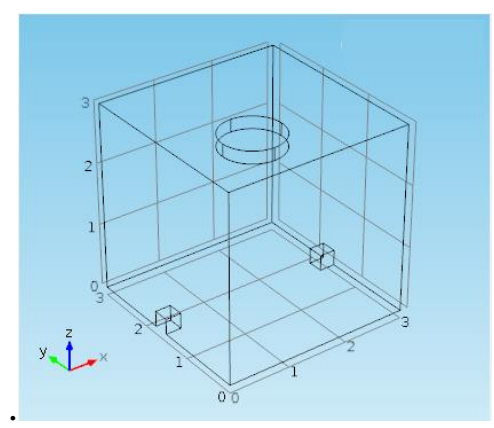

(a)

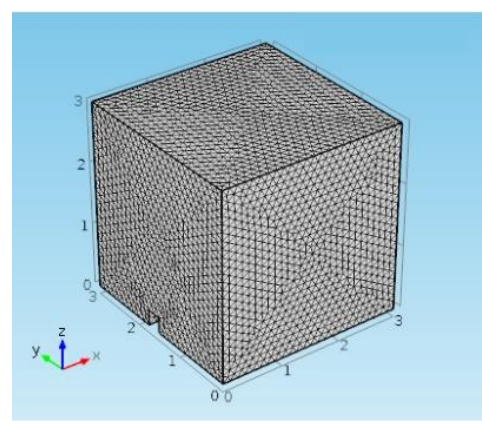

(b)

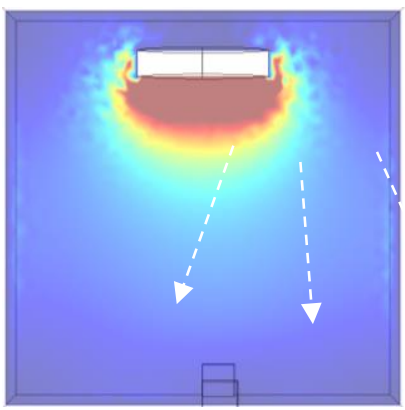

(c) 
Figure 6. Finite element modeling. (a) the model shows position of fan in a room, (b) mesh for finite element calculation, (c) Distribution pattern of airflow velocity and air particles movement due to the positioning of fan on the ceiling.

Figure 7 shows the contact angle measurement between the droplet and floor material using a laboratory microscope. The measurement of contact angle between the droplet-sized liquid droplets and some flooring material types shows that the contact angle is always less than 90 degrees.

Micro droplet contact angle with ceramic floor $=25$ degrees, Vinyl (PVC) floor contact angle $=34$ degrees, Polyurethane coated wood flooring contact angle $=66$ degrees. The value of the liquid's contact angle to the floor material, which is less than 90 degrees, indicates that the liquid droplets tend to stick firmly to the floor due to the adhesion mechanism between the fluid and the floor material. The surface tension between the liquid and the floor is greater than the liquids' surface tension so that the aerosol grains and microdroplets will stick to the floor, will not bounce upwards, and will not roll. Indoor air will be cleaner from aerosols and micro-droplets that may be contaminated with viruses. A liquid-floor contact angle that is less than 90 degrees indicates hydrophilic or floor "likes" with the existence of water.

\section{Conclusions and Recomendations}

The numerical airflow simulation shows that positioning the fan on the ceiling causes the airflow to blow the micro-droplets falling faster to the floor. Therefore microdroplets and aerosol will concentrate on the floor and move away from the most risk human organ for Covid 19 transmission, namely the mouth and nose.

The experiments of the contact angle on the several floor materials always show fewer than 90 degrees. Therefore micro-droplets or aerosols that fall on the floor will stick tightly and not easy rolling. These phenomena will cause the room to become more sterile from aerosols and micro-droplets contaminated with Covid19. The room will be healthier and safer.

The technique of creating a vertical downward airflow by installing fans on the ceiling of a closed room can be done massively, cheap, but effective way to clean aerosols and microdroplets in the air which may be contaminated with covid19 viruses so that they fall as quickly as possible on the floor. Then, the floor can be periodically disinfected by wiping or mopping. After passengers get off the vehicle, the train floor, KRL, or city bus can be redisinfected by UV-C lighting, spraying, or wiping it so that the virus on the floor becomes inactive. 


\section{Droplet on wood coated by Polyurethane}

Wood floor coated by Polyurethane

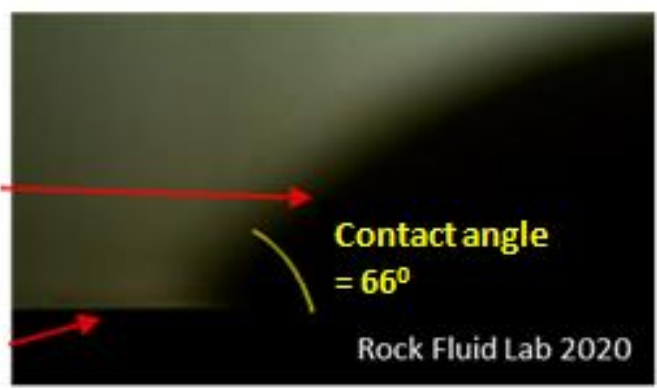

(a)

Droplet on Ceramic

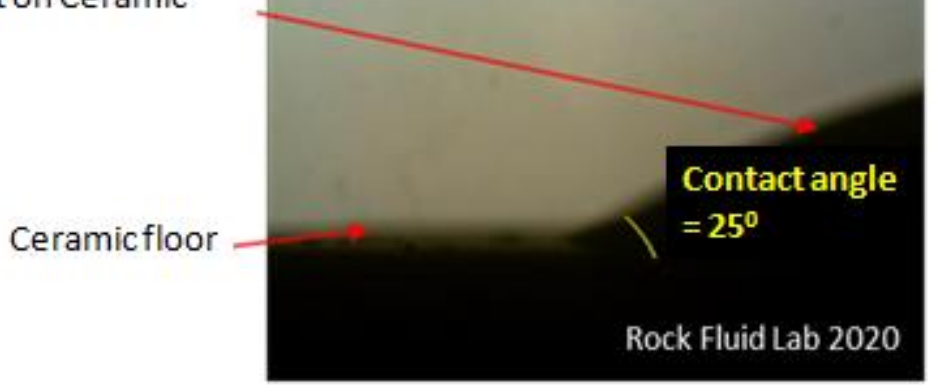

(b)

Droplet on Vynil (PVC)

Vynilfloor (PVC)

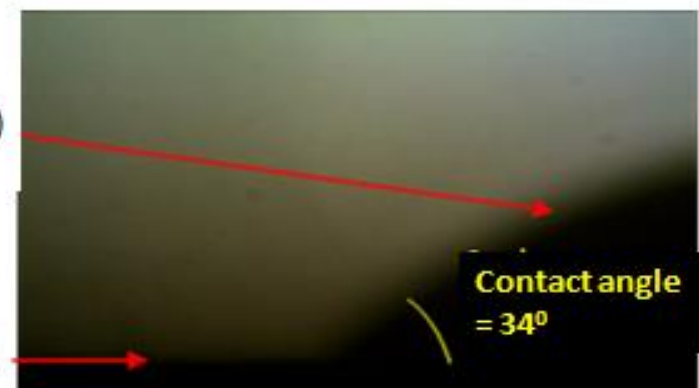

Rock Fluid Lab 2020

(c)

Figure 7. The contact angle of droplet grains on the various floor materials, measured using "Contact angle microscope". (a) contact angle with polyurethane polished wood floors, (b) contact angle with ceramic floors, (c) contact angle with PVC vinyl carpet.

\section{References}


Aganovic, A., Cao, G., Stenstad, L.-I., \& Skogås, J. G. (2017). Impact of surgical lights on the velocity distribution and airborne contamination level in an operating room with laminar airflow system. Building and Environment, 126, 42-53. https://doi.org/10.1016/j.buildenv.2017.09.024

Bodey, G., Freireich, E., \& Frei, E. (1969). Studies of patients in a laminar air flow unit. Cancer, 24(5), 972-980. PubMed. https://doi.org/10.1002/10970142(19691 1)24:5<972::aid-cncr2820240516>3.0.co;2-k

Di Mundo, R., Petrella, A., \& Notarnicola, M. (2018). Surface and bulk hydrophobic cement composites by tyre rubber addition. Construction and Building Materials, 172, 176184. https://doi.org/10.1016/j.conbuildmat.2018.03.233

Evans, R. P. (2011a). Current Concepts for Clean Air and Total Joint Arthroplasty: Laminar Airflow and Ultraviolet Radiation: A Systematic Review. Clinical Orthopaedics and Related Research®, 469(4), 945-953. https://doi.org/10.1007/s1 1999-010-1688-7

Evans, R. P. (2011b). Current Concepts for Clean Air and Total Joint Arthroplasty: Laminar Airflow and Ultraviolet Radiation: A Systematic Review. Clinical Orthopaedics and Related Research ${ }^{\circledR}, 469(4)$, 945-953. https://doi.org/10.1007/s1 1999-010-1688-7

Friberg, B. (1998). Ultraclean Laminar Airflow ORs. AORN Journal, 67(4), 841-851. https://doi.org/10.1016/So001-2092(06)62647-1

Hindawi, S. I., Hashem, A. M., Damanhouri, G. A., El-Kafrawy, S. A., Tolah, A. M., Hassan, A. M., \& Azhar, E. I. (2018). Inactivation of Middle East respiratory syndromecoronavirus in human plasma using amotosalen and ultraviolet A light. Transfusion, 58(1), 52-59. https://doi.org/10.1111/trf.14422

Holder, C. D. (2012). The relationship between leaf hydrophobicity, water droplet retention, and leaf angle of common species in a semi-arid region of the western United States. Agricultural and Forest Meteorology, 152, 11-16. https://doi.org/10.1016/j.agrformet.2011.08.005

Morawska, L., \& Milton, D. K. (2020). It Is Time to Address Airborne Transmission of Coronavirus Disease 2019 (COVID-19). Clinical Infectious Diseases, 71(9), 2311-2313. https://doi.org/10.1093/cid/ciaa939

Nurhandoko, B. E. (2020, March 24). Spektrum Sinar Matahari mengandung Desinfektan Alami.

https://www.researchgate.net/publication/340130061_Spektrum_Sinar_Matahari_ mengandung_Desinfektan_Alami

Riediker, M., \& Tsai, D.-H. (2020). Estimation of Viral Aerosol Emissions From Simulated Individuals With Asymptomatic to Moderate Coronavirus Disease 2019. JAMA Network Open, 3(7), e2013807-e2013807. https://doi.org/10.1001/jamanetworkopen.2020.13807

Sagripanti, J.-L., Voss, L., Marschall, H.-J., \& Lytle, C. (2012). Inactivation of Vaccinia Virus by Natural Sunlight and by Artificial UVB Radiation. Photochemistry and Photobiology, 89. https://doi.org/10.1111/j.1751-1097.2012.01207.x

Satgas Penanganan COVID-19. (2021). Lonjakan kasus dampak abaikan protokol kesehatan. https://covid 19.go.id/berita/lonjakan-kasus-dampak-abaikan-protokol-kesehatan

Thomas, S., Thomas, R., Zachariah, A., \& Mishra, R. (2017). Thermal and Rheological Measurement Techniques for Nanomaterials Characterization. In Thermal and 
Rheological Measurement Techniques for Nanomaterials Characterization. https://doi.org/10.1016/B978-0-323-46139-9.18001-6

Toho University. (2020). SARS-CoV-2 Coronavirus Micro-droplets-NHK World report. https://www.youtube.com/watch?v=vBvFkQizTT4

Tran, K., Cimon, K., Severn, M., Pessoa-Silva, C., \& Conly, J. (2013). Aerosol-Generating Procedures and Risk of Transmission of Acute Respiratory Infections: A Systematic Review. CADTH Technology Overviews, 3, e3201.

Weiss, M., Weiss, P., Weiss, D., \& Weiss, J. (2007). Disrupting the Transmission of Influenza A: Face Masks and Ultraviolet Light as Control Measures. American Journal of Public Health, 97 Suppl 1, S32-7. https://doi.org/10.2105/AJPH.2006.096214

WHO. (2019). WHO Infection Prevention and Control Guidance for COVID-19. https://www.who.int/emergencies/diseases/novel-coronavirus-2019/technicalguidance/infection- prevention-and-control

WHO. (2020). Modes of transmission of virus causing COVID-19: Implications for IPC precaution recommendations. https://www.who.int/newsroom/commentaries/detail/modes-of- transmission-of-virus-causing-covid-19implications-for-ipc-precaution-recommendations 